\title{
OPTIMIZATION OF TRANSPORT PROCESSES WITH THE USE OF INFORMATION TECHNOLOGIES
}

Georgiy Prokudin, Professor, Dr. Sci.

Olexiy Chupaylenko, As. Professor, Ph.D.

Olexiy Prokudin, As. Professor

Olexiy Dudnik, As. Professor

Yuriy Pylypenko, Aspirant

Ukraine, Kyiv,National Transport University

DOI: https://doi.org/10.31435/rsglobal_ejits/30112018/6217

\section{ARTICLE INFO}

Received 22 June 2018

Accepted 12 November 2018

Published 30 November 2018

\section{KEYWORDS}

freight, logistics, information

technology, salesman-task,

optimization, route.

Citation: Georgiy Prokudin, Olexiy Chupaylenko, Olexiy Prokudin, Olexiy Dudnik, Yuriy Pylypenko (2018) Optimization of Transport Processes With the Use of Information Technologies. European Journal of Intelligent Transportation Systems. 1(1). doi: 10.31435/rsglobal_ejits/30112018/6217

Copyright: (C) 2018 Georgiy Prokudin, Olexiy Chupaylenko, Olexiy Prokudin, Olexiy Dudnik, Yuriy Pylypenko. This is an open-access article distributed under the terms of the Creative Commons Attribution License (CC BY). The use, distribution or reproduction in other forums is permitted, provided the original author(s) or licensor are credited and that the original publication in this journal is cited, in accordance with accepted academic practice. No use, distribution or reproduction is permitted which does not comply with these terms.

Introduction. The use of information technology to optimize transport processes of international cargo transportation will result in a reduction in transportation costs of up to $20 \%$ of total costs. The traveling salesman method allows you to find such a route between customers, which provides the shortest closed trip cycle [1].

The traveling salesman leaves the first city, visits only once each of $n$ cities and returns to the first city. The distances between cities are known. The challenge is to find a route to cities, which ensures the shortest closed cycle of salesman's travel [2].

A detailed analysis of applying the model of the optimal purpose to solve the traveling salesman problem has shown that in this model, in addition to $\mathrm{n}$ ! Hamiltonian (full) contours there are also many incomplete (isolated) contours that cover only certain groups of cities. This fact greatly complicated the solving of the traveling salesman problem and made the researchers look for other more effective methods of its solution.

Purpose of the study: development of a computer program of optimization of transport routes in the implementation of international transportation on the basis of solving the problem of salesman.

Material and methods. This study is mainly focused on the use of modern information technology means in solving the traveling salesman problem to optimize the routing of freight transportation in international traffic [2]. 
The importance of information technology application in the transport sector is indisputable. Optimization of freight delivery schemes is very important in the transport industry and logistics [3]. In most segments of the market, the delivery of goods adds to its value an amount equivalent to the cost of the product itself. In addition, it should be noted that the use of modern information technology for optimization of such delivery leads to minimization of costs, often at least from 5 to $20 \%$ of the product total cost [4].

The most important factors that need to be considered in solving the problem are: the distances between points of departure and destination, and customs posts; time of service at checkpoints (customs clearance); time of loading and unloading operations; average speed of the vehicle; time of rest under the European agreement regarding the work of vehicle crews, which perform international automobile transportation. Data on these characteristics is proposed to be transformed into a Microsoft Excel spreadsheet file. The software for solving the salesman problem is designed using the Delphi programming algorithmic language [5].

There are several separate cases of general problem statement, in particular the geometric problem of traveling salesman (the so-called planar or Euclidean, when the distance matrix reflects the distance between points on the plane), the triangular problem of traveling salesman (when the triangle is inequality in the value matrix), the symmetric and asymmetric travel salesman problems. There is also a generalization of the task, the so-called generalized saleswoman's task [6].

Research results. To begin the calculations, we create a page for entering the input data for further calculations, namely the time characteristics of loading and unloading operations in this route. It should be noted that with regards to adding to the route of intermediate points, the program works in two modes: manual and automatic.

That is, intermediate points can be determined independently, or the program does it automatically, choosing the closest to the point of departure.

The developed program generates a corresponding table that clearly shows the distances between the specified cities and the intermediate points. Thanks to what we can build a possible closed route and be able to choose from all options the shortest.

It is established that using a combinatorial method, the program automatically calculates the total distance of the route and chooses the one where the distance between the cities is the shortest [7]. A detailed analysis of the application of the model for optimal assignment to the salesman problem has shown that in this model, in addition to the Hamiltonian (full) circuits, there are also many incomplete (isolated) contours that cover only certain groups of cities [7].

The program generates a table, which clearly shows the distances between the specified cities and the intermediate points. It allows finding possible closed routes and choosing the shortest of all variants (Fig. 1) [8].

Based on the combinatorial method, the program automatically calculates the total distance of the route and selects the one where the distance between the cities is the shortest. During this study, the use of the Delphi Software and the function "Search Solution" in the Microsoft Office Excel table processor in solving the traveling salesman problem to optimize the routing of freight transportation in international traffic is motivated in this article. The existing requirements and restrictions on the specificity and dimension of the problem are considered as well.

\section{Conclusions}

1. The possibility of automating the process of solving the salesman's task with the help of modern means of information technologies, namely: Delphi software environment and the "Search solution" function in the Microsoft Office Excel table processor, is proved.

2. The program of transport optimization takes into account existing requirements and restrictions on the specificity and dimension of the task. 


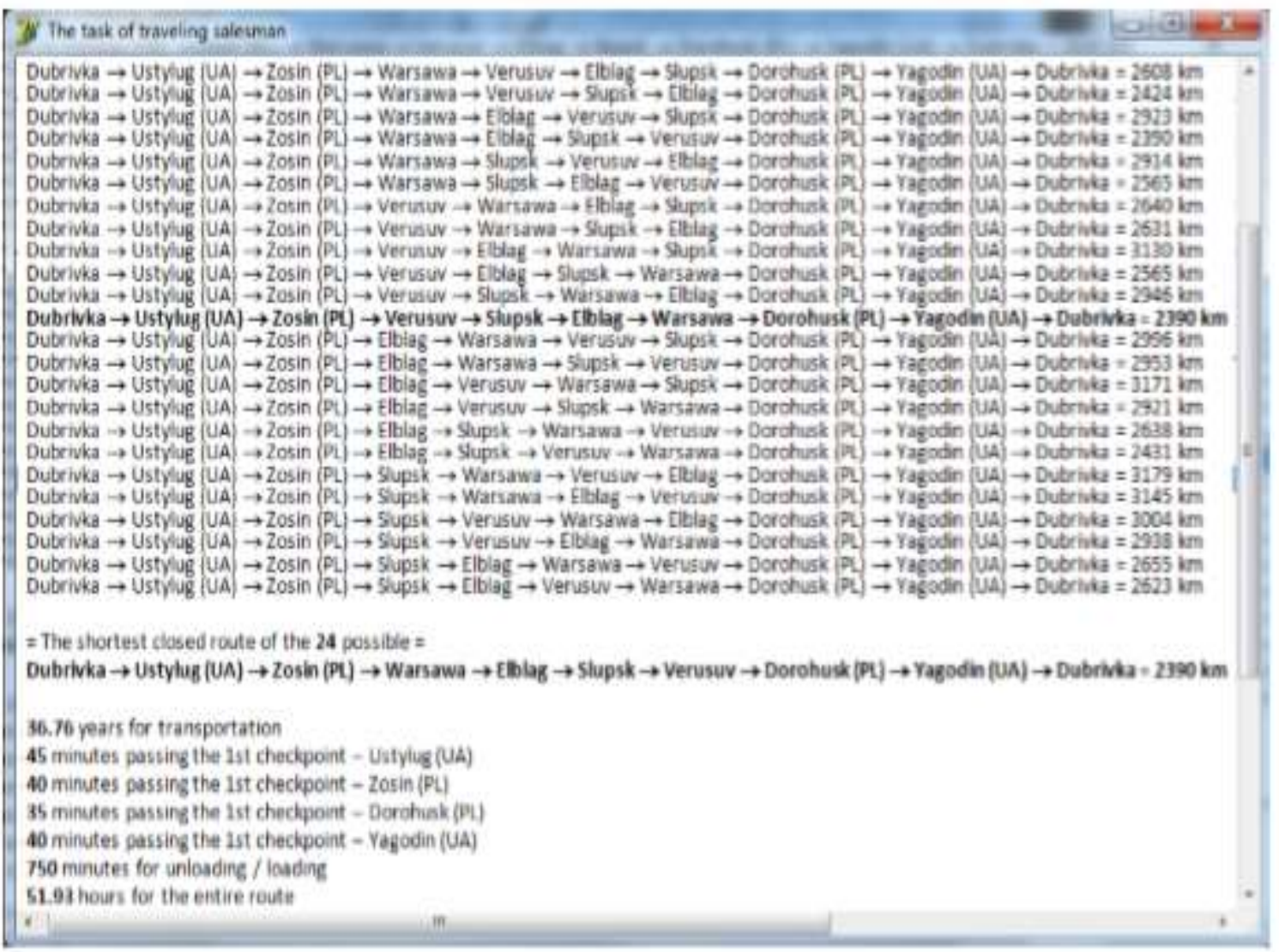

Fig. 1. Result of the program work

\section{REFERENCES}

1. Kozachenko, D., Vernygora, P., Malashkin, V. (2015). Fundamentals of operations research in transport systems: examples and tasks. DNUZT Publ., 277 p. (in Ukrainian).

2. Kunda, N. (2008). Operations research in transport systems. Vydavnychyi Dim "Slovo" Publ., 400 p. (in Ukrainian).

3. Lashenykh, O., Kuzkin, O. (2006). Methods and models of optimization of transport processes and systems. ZNTU Publ., 435 p. (in Ukrainian).

4. Prokudin, G., Danchuk, V., Tsukanov, O., Tsymbal, N. (2013). Computer technology statistical analysis of transport. NTU Publ., 280 p. (in Ukrainian).

5. Prokudin, G. (2006). Models and methods of optimization of transportation in transport systems. NTU Publ., 224 p. (in Ukrainian).

6. Johnson, D. (1990). Local Optimization and the Traveling Salesmen Problem. Springer-Verlag, 446-461 (in Russian).

7. Prokudin, O. (2014). Information technology functioning transport logistics Production Enterprise. Informatsiini protsesy, tekhnologii ta systemy, 1, 38-49 (in Ukrainian).

8. Kuzmychov, A., Medvediev, M. (2005). Mathematical Programming in Excel. EU Publ., 320 p. (in Ukrainian). 